Ann N Y Acad Sci. 2012 April ; 1253: . doi:10.1111/j.1749-6632.2012.06492.x.

\title{
Glycobiology of immune responses
}

\author{
Gabriel A. Rabinovich ${ }^{1,2}$, Yvette van Kooyk ${ }^{3}$, and Brian A. Cobb ${ }^{4}$
}

${ }^{1}$ Laboratorio de Inmunopatología, Instituto de Biología y Medicina Experimental (IBYME), Consejo Nacional de Investigaciones Científicas y Técnicas (CONICET) ${ }^{2}$ Laboratorio de Glicómica Funcional, Departamento de Química Biológica, Facultad de Ciencias Exactas y Naturales, Universidad de Buenos Aires, C1428 Ciudad de Buenos Aires, Argentina ${ }^{3}$ Department of Molecular Cell Biology and Immunology, VU University Medical Centre, Amsterdam, the Netherlands ${ }^{4}$ Department of Pathology, Case Western Reserve University School of Medicine, Cleveland, Ohio

\section{Abstract}

Unlike their protein "roommates" and their nucleic acid "cousins," carbohydrates remain an enigmatic arm of biology. The central reason for the difficulty in fully understanding how carbohydrate structure and biological function are tied is the nontemplate nature of their synthesis and the resulting heterogeneity. The goal of this collection of expert reviews is to highlight what is known about how carbohydrates and their binding partners-the microbial (non-self), tumor (altered-self), and host (self) — cooperate within the immune system, while also identifying areas of opportunity to those willing to take up the challenge of understanding more about how carbohydrates influence immune responses. In the end, these reviews will serve as specific examples of how carbohydrates are as integral to biology as are proteins, nucleic acids, and lipids. Here, we attempt to summarize general concepts on glycans and glycan-binding proteins (mainly C-type lectins, siglecs, and galectins) and their contributions to the biology of immune responses in physiologic and pathologic settings.

\section{Keywords}

glycobiology; glycoimmunology; glycans; lectins; C-type lectins; siglecs; galectins

\section{Glycobiology-an overview}

Calling nucleic acids "cousins" of carbohydrates is an accurate representation of the fact that both DNA and RNA are essentially polysaccharides composed of phosphate-linked polyribose cores. Without carbohydrates, nucleic acids would not form the linear scaffolding required for their function. Likewise, proteins and carbohydrates can be termed "roommates" because, in mammals, carbohydrates are nearly always associated with either proteins or lipids. With some notable exceptions (e.g., $\beta_{2}$-microglobulin and the galectin family), all secreted proteins and all cell surface proteins and lipids contain significant amounts of covalently attached glycans. In some cases the molecular mass of a glycoprotein can be as much as $50 \%$ carbohydrate or more, ${ }^{1}$ with the carbohydrates falling into two

(C) 2012 New York Academy of Sciences.

Addresses for correspondence: Gabriel A. Rabinovich, gabyrabi@gmail.com; Yvette van Kooyk, Y.vanKooyk@vumc.nl; or Brian A. Cobb., brian.cobb@case.edu.

Conflicts of interest

The authors declare no conflicts of interest. 
categories, N-linked or O-linked (Fig. 1), depending on the nature of the linkage to the underlying protein backbone. ${ }^{2,3}$ Molecular pathways required for $\mathrm{N}$ - and O-linked carbohydrate pathways, or at least primitive versions of them, are also present in the microbial world, with the most remarkable example being Campylobacter species that can add both $\mathrm{O}$ - and $\mathrm{N}$-linked carbohydrates to their proteins (e.g., flagellin). ${ }^{4}$ Importantly in humans, loss of genes in these pathways (conditions known as congenital disorders of glycosylation) is often embryonically lethal; but when individuals survive, the pathologies present are typically quite devastating. ${ }^{5-7}$ Remarkably, the mammalian glycome repertoire is estimated to include thousands of glycan structures generated by the concerted action of an endogenous group of glycosyltransferases and glycosidases. ${ }^{8}$

The general physiologic roles of carbohydrates and their binding partners are highly diverse and include critical functions in cell-cell communication and adhesion, ${ }^{9}$ protein structural stability, ${ }^{10}$ membrane structure, ${ }^{11}$ and cellular signaling. ${ }^{12}$ Indeed, while carbohydrates play as varied roles in biology as proteins do, they have been problematic to study due to the inherent differences between the complex synthetic pathways for carbohydrates and the template-driven synthesis of nucleic acids and proteins, and this has unfortunately led many investigators to ignore the "complicating factor" that carbohydrates can seem to represent. One particularly stark example is the understanding of protein structure and function, much of which depends on the decades of crystallography that have created a cache of structural information with which we interpret key functional data. Protein crystallography depends on well-ordered crystals forming. But the typical mammalian pattern of glycosylation often precludes the formation of high-quality crystals. As a result, the approaches to determining the three-dimensional structure of a glycoprotein include recombinant overexpression in $E$. coli to prevent the addition of glycans completely ${ }^{13}$ and expression in Sf9 insect cells, ${ }^{14}$ which produces proteins that carry only limited mannose structures that resemble the hybrid $\mathrm{N}$-glycan structures shown in Figure 1 and are more homogeneous than the mammalian counterparts. ${ }^{15}$ At the same time, a wealth of data have shown that fully complex-type glycans characteristic of mammalian glycoproteins are required for native function. One can immediately recognize the problem with assigning a single structure or function-or a list of binding partners - to a glycoprotein when the protein used in the experiments lacks the native glycosylation patterns found in vivo. As of 2011, the reality is that our structural knowledge of how carbohydrates - integral components of proteins - (possibly as many as $80-90 \%$ of all human proteins are glycosylated) may affect function remains in its infancy.

Another point worth making is the issue of heterogeneity, the central complicating aspect of glycobiology. Complex-type $N$-glycans, for example, are hallmarks of mammalian glycoproteins, and as one moves down the evolutionary ladder protein glycosylation becomes simpler despite the genetic similarities among organisms. As such, it seems entirely reasonable to suggest that the inherent heterogeneity associated with these pathways is integral to their function in biology. The reductionist in each of us wants our experiments to be as clean as possible by limiting the variables, but perhaps it is the very molecular heterogeneity that we try to avoid in experiments that is the key to unlocking our understanding life and the differences among species and differences associated with disease. If correct, it is impossible to study systems biology in the absence of understanding and investigating the contributions of glycobiology and the underlying carbohydrate heterogeneity to biological processes.

Although one can paint a relatively bleak picture of our ability to dissect the global complexities of carbohydrate biological function, the last decade has seen some remarkable progress in terms of the creation of tools to determine glycan structure and diversity, as well as in the collaborative efforts to pool expertise in tackling the "glycomics problem." Under the leadership of James Paulson at the Scripps Research Institute, the Consortium for 
Functional Glycomics (CFG) was created and funded by the National Institute of General Medical Sciences. Although the ten years of funding is now complete, the CFG was responsible for the creation and development of numerous tools to assist investigators with understanding the role of carbohydrates in a variety of biological systems. One particularly important resource is the glycan-binding array in which hundreds of carbohydrates representing a wide variety of structures were covalently attached to a chip for binding studies. ${ }^{16}$ Another key resource created by the CFG is a gene chip including genes that encode all carbohydrate-associated proteins and pathway enzymes, which enables studies on the regulation of glycosylation and other mechanisms as a function of disease state. ${ }^{17}$ The collective efforts represented by the CFG and other worldwide efforts, such as EuroCarb and the Japanese Consortium for Glycobiology and Glycotechnology, the world of glycomics has begun to open to the nonspecialist and will likely lead to rapid progress in understanding the multifaceted roles of carbohydrates in physiology.

\section{Glycans and the immune system-an introduction}

The focus of this issue of Annals of the New York Academy of Sciences is one part of the overall picture of carbohydrate structure and function: the immune system. The immune response is an ideal system in which to begin painting a larger picture of carbohydrates and their role in biology, because of the importance of glycans and their binding partners in nearly every aspect of immunology (Fig. 2).

As with all cells, essentially all surface-localized immune receptors are glycoproteins, including pattern recognition receptors (PRRs) such as toll-like (TLR) and NOD-like receptors, the class I and class II major histocompatibility complex proteins (MHC class I and MHC class II), chemokine receptors, cytokine receptors, T and B cell coreceptors, and the $\mathrm{T}$ and $\mathrm{B}$ cell receptors themselves. The role of the glycans on these molecules is as varied as the molecules themselves. For example, prevention of complex-type $N$-glycan synthesis on $\mathrm{T}$ cells substantially increases $\mathrm{T}$ cell receptor signaling, making $\mathrm{T}$ cell activation much less stringent. ${ }^{18}$ In addition, the loss of complex-type $\mathrm{N}$-glycans on MHC II significantly impedes the ability to present bacterial polysaccharides to T cells, ${ }^{19}$ whereas mutagenesis of TLR molecules to remove sites of glycosylation directly influences their signaling. ${ }^{20,21}$

Other components of the immune system are the various glycan-binding proteins (GBPs) or lectins, including the C-type lectins, siglecs, and galectins. Through binding to lectins and sterically modulating molecular interactions, mammalian glycans participate in a diversity of cellular mechanisms that contribute to innate and adaptive immune responses. ${ }^{8}$ The theme with these molecules is that they are carbohydrate-binding molecules, and they also tend to be glycoproteins, with the exception of the galectin family. One well-known family member is DC-SIGN, a C-type lectin receptor (CLR) found on the surface of dendritic cells (DCs) that serves to bind a variety of mannose- and fucose-containing ligands, including glycoproteins of the envelope of human immunodeficiency virus (HIV), and signals into the cell for activation. ${ }^{22}$ Another example is CD22, a member of the siglec (sialic acid-binding Ig-like lectin) family and a crucial part of the B cell receptor complex that assists with antigen uptake and B cell activation. ${ }^{23,24}$ Finally, the galectins are thought to be able to associate with host glycans, such that the cell surface can be organized into receptor lattices for optimal receptor spacing and signaling. ${ }^{11,25}$

Secreted glycoproteins in the immune system include essentially all cytokines and chemokines, many of the complement components, and antibodies. One recent and important discovery is that the $\mathrm{N}$-glycans attached to the $\mathrm{Fc}$ portion of IgG molecules modulate antibody activity, ${ }^{26,27}$ for example, antibodies' terminal sialic acids send an 
inhibitory signal to responding immune cells, whereas those missing terminal sialic acids send activating signals. Another pathway to note is the lectin pathway for complement activation, which requires the mannose-binding lectin and ficolins, rather than the classical components such as $\mathrm{C} 1 \mathrm{q} .{ }^{28}$

Two other areas of note are lymphocyte development and leukocyte homing. The Notch family of molecules relies upon glycan changes, especially the addition of fucose residues, to mediate $\mathrm{T}$ and $\mathrm{B}$ cell differentiation into the various known lineages from common progenitors. ${ }^{29}$ For homing, migrating cells rely upon the selectin family of adhesion molecules on circulating leukocytes; the selectins bind to specific carbohydrates expressed on the surface of endothelial cells near sites of inflammation and infection. ${ }^{30,31}$ This enables the cells to home to sites where they are needed.

Turning to microbes, a majority of their immunogens are glycans or glycan conjugates, and nearly all bacteria and viruses are coated with a thick glycocalyx (sugar coat). For HIV, its often-cited gp120 coat protein is glycosylated to the point that most of the underlying protein is inaccessible to antibodies. ${ }^{32}$ Some bacteria are completely encapsulated with polysaccharides, ${ }^{33}$ whereas others have thick coats of endotoxin and other glycolipids. Gram-positive bacteria also have externally exposed peptidoglycans. From these groups, essentially all of the so-called pathogen-associated molecular patterns can be found (e.g., endotoxin/LPS, viral coats, muramyl dipeptide, and bacterial capsules). An important point is that many pathogens have evolved to make host-like carbohydrates at their cell surface to mimic the host and evade immune detection. ${ }^{34}$ This fact alone shows the importance of carbohydrate immunogens, because if the immune system did not recognize carbohydrates specifically, there would be no need to be tolerant of self-carbohydrates, and pathogens would not be able to hide through mimicry.

Although the diversity of glycans and GBPs, coupled with the diversity of pathways involved in shaping and directing the immune response, is as broad as immunology itself, this issue touches on several key topics under active investigation around the world. These areas are described below and further elaborated on in the papers collected in this special issue. $^{\mathrm{a}}$

\section{GBPs in self, non-self, and altered-self recognition}

Several GBPs are expressed on cells of the immune system and/or released to the extracellular milieu where they play essential roles in the control of innate and adaptive immunity. ${ }^{35}$ These include the families of CLRs, siglecs, and galectins that mainly function through recognition of defined carbohydrate structures decorating glycoproteins or glycolipids. ${ }^{35}$ All these GBPs carry one or more carbohydrate recognition domains (CRD) that coordinate the interaction with a specific glycan. CLRs are calcium-dependent carbohydrate binding proteins, where specific amino acids in the CRD coordinate the carbohydrate ligand and a $\mathrm{Ca}^{2+}$ ion. ${ }^{36} \mathrm{C}$-type lectins that contain an Glu-Pro-Asn (EPN) amino acid motif, such as DC-SIGN, mannose receptor (MR), Langerin, and L-SIGN/DCSIGNR, ${ }^{37}$ have specificity for mannose- and/or fucose-terminated glycans. In contrast, galactose-specific C-type lectins like macrophage galactose lectin (MGL) and DCASGPR,${ }^{38,39}$ which contain the Gln-Pro-Asp (QPD) sequence in the CRD, recognize galactose-terminated or $\mathrm{N}$-acetylgalactosamine (GalNAc)-terminated glycan structures. The type II subfamily of CLRs, of which 17 members have been cloned in humans, is mainly restricted to antigen-presenting cells (APCs) such as macrophages and DCs, whereas some

aRabinovich, G., Cobb, B., van Kooyk, Y., eds. 2012. Glycobiology of the Immune Response. Special issue, Ann. N.Y. Acad. Sci. 1253. 
of them have also been identified on NK cells or endothelial cells. ${ }^{40}$ Most C-type lectins have internalization motifs in their cytoplasmic tail and play a role in the uptake of glycosylated antigens that they recognize. ${ }^{41,42}$ In particular, CLRs are involved in antigen presentation, as they take up and route antigens to the MHC class II loading compartments to present the antigen in the context of MHC class II molecules to prime antigen-specific $\mathrm{CD} 4{ }^{+} \mathrm{T}$ cell responses. ${ }^{43}$ Several C-type lectins expressed on DCs have also been reported to shuttle antigen intracellularly to the MHC class I loading compartment through a yet uncharacterized cross-presentation route, thereby promoting antigen-specific $\mathrm{CD} 8^{+} \mathrm{T}$ cell responses. ${ }^{44-47}$ CLRs can have inhibitory or activating domains in the cytoplasmic tail, leading to signaling that either negatively or positively influences immune responses. ${ }^{37,48}$ This illustrates that amino acid sequences of CLRs can have profound regulatory functions in antigen processing and presentation for instructing $\mathrm{T}$ cells and altering signaling cascades.

Mice also express C-type lectins, but certain members of the mouse CLR family differ substantially from human CLRs, making the direct comparison of mouse data to a human setting difficult. For example, DC-SIGN has various homologues in the mice, such as SIGNR1, SIGNR3, and mDC-SIGN. ${ }^{49}$ In total, seven DC-SIGN homologues have been identified, but none of them has the exact APC-restricted expression or glycan specificity as human DC-SIGN. Also, for human MGL, which exhibits GalNAc specificity, two mouse homologues have been described, MGL1 and MGL2, with glycan specificity of Le ${ }^{\mathrm{X}}$ and GalNAc, respectively. ${ }^{50,51}$ On the other hand, some CLRs can be quite homologous between human and mice, such as Langerin, on Langerhans cells in the skin, and Dectin-1, which recognizes $\beta$-glucans on yeasts. ${ }^{52}$

GBPs have been shown to be involved in pathogen binding and therefore function as PRRs through the recognition of glycans exposed on pathogens, ranging from viruses and bacteria to yeasts and parasites. ${ }^{23}$ In particular those receptors with glycan specificity for Lewis and mannose glycans (such as DC-SIGN) have been shown to bind a multitude of pathogens, such as HIV-1 and other viruses, bacteria such as Mycobacterium tuberculosis and Helicobacer pylori, helminths such as Schistosoma mansoni, and yeasts such as Candida albicans. ${ }^{23,48,53,54}$ Glycan structures on these pathogens-high mannose, Lewis X or Lewis $\mathrm{Y}$, or LDNF-are recognized by DC-SIGN. Pathogen-binding CLRs are also internalization receptors, by which recognition of pathogens results in the uptake of the pathogen by APCs. ${ }^{55}$ Because CLRs play essential roles in the recognition of pathogens, they are formally considered PRRs, similar to TLRs; however, the function of CLRs is distinct from TLRs because the latter are not thought to internalize antigens for processing and presentation by MHC class I or II molecules. Surprisingly, many reports also illustrate the different signaling function that CLRs play by interfering with TLRs or $\mathrm{Fc}$ receptor $(\mathrm{FcR})$ triggering. In particular, CLRs may signal via Syk- or Raf-1-dependent pathways upon interactions with specific glycans. ${ }^{48,56,57}$ CLRs are equipped with signaling motifs in their cytoplasmic tails and/or associate with signaling complexes, although some CLRs (e.g., DCSIGN) may only induce gene expression in the presence of other PRRs. Upon recognition of fungal $\beta$-glucan structures, the well-described CLR Dectin-1 triggers signaling through the Syk tyrosine kinase and activation of ERK- and JNK-mediated cascades, which, in turn, activate the transcription factor nuclear factor kappa B (NF- $\kappa \mathrm{B}) .{ }^{48,52,58}$ These signaling events are dependent on the adaptor CARD9 and are independent of TLR signaling. Other CLRs, such as DC-SIGN, interact with mycobacterial ManLAM, and thereby promote the production of proinflammatory cytokines, such as IL-6 and IL-12, via a Raf-1-mediated signaling pathway. In contrast, fucose interaction with DC-SIGN initiates Raf-1independent signaling pathways, resulting in the induction of anti-inflammatory cytokines, such as IL-10, and inhibition of proinflammatory cytokines, such as IL-6 and IL-12. ${ }^{57}$ This illustrates the notion that the glycan signature of pathogens can trigger different signaling processes, all through the same CLR. 
Most GBPs are not pathogen-restricted, as they often interact with self-glycoproteins that have exposed mannose/fucose or GalNAc glycan structures. ${ }^{59}$ These glycans can be found on proteins or lipids, and the multivalency of glycans can often increase the avidity to GBPs. ${ }^{60}$ Tumor antigens commonly show an altered glycan composition that is reflected by a shorter glycosylation backbone or by the multivalent exposure of glycan epitopes on repeated sequences. This is well illustrated by the mucin repeated sequences in the tumor antigen MUC-1, which shows increased binding to MGL, or by the binding of tumorspecific carcinoembryonic antigen (CEA) to DC-SIGN. ${ }^{61,62}$ Most often, GBPs can recognize single glycan structures; but in a few cases the protein backbone is also crucial for specific glycans to be recognized by CLRs. As an example, DC-SIGN does not recognize sialylated glycans, yet sialylated IgGFc is recognized by DC-SIGN and has been shown to contribute to the anti-inflammatory activity of intravenous immunoglobulins (IVIGs), together with the inhibitory FcR FcyRIIB, in promoting the production of the Th2-type cytokine IL-33 and expansion of IL-4+ basophils. $^{26}$

Pathogens can also display specific glycans, as exemplified by helminth glycans such as LDNF (GalNAc $\beta 1-4$ (Fuca 1-3)GlcNAc-R) and LDN (GalNAc $\beta 1-4$ GlcNAc-R) that can interact with GBPs with high affinity. ${ }^{53}$ Other pathogens, such as HIV-1, display highmannose structures that are not particularly pathogen-specific but show high-affinity interactions for certain GBPs, such as the C-type lectins DC-SIGN, MR, langerin, and dendritic cell immunoreceptor (DCIR). ${ }^{63-65}$ CLRs such as DC-SIGN, MR, or MGL are well-known to recognize endogenous glycoproteins, and thereby function as adhesion molecules, signaling receptors, or antigen uptake mediators. ${ }^{66}$ DC-SIGN has been demonstrated to interact with ICAM-2 and ICAM-3 to mediate cell adhesion and rolling of DCs due to expression of Lewis Y on endothelial cells. DC-SIGN has also been reported to interact with Lewis X (Fig. 1) and Y glycans present on Mac-1 and CEACAM-1 on neutrophils, thereby allowing regulated adhesion between neutrophils and DCs. ${ }^{67}$ The presence of GalNAc on CD45 expressed by effector memory $\mathrm{CD}^{+}$and $\mathrm{CD} 8^{+} \mathrm{T}$ cells has been shown to interact with the C-type lectin MGL, found mainly on tolerogenic APCs, and induce apoptosis and proliferation of these cells-demonstrating a homeostatic regulatory role of glycans exposed on CD45. ${ }^{68}$ Furthermore, C-type lectins such as MR, Langerin, and DC-SIGN also recognize tissue antigens, for example serum hydrolases, tissue plasminogen activator, type I collagen, and Fc-IgG. Because MR, Langerin, and DC-SIGN have internalization capacity, their uptake serves to control homeostatic surveillance by APCs, such as DCs and macrophages. ${ }^{35}$

Similar to CLRs, siglecs are cell surface GBPs capable of conveying regulatory signals that positively or negatively control immune responses. Although most siglecs are known to be negative regulators of cell signaling, because they contain immune receptor tyrosine-based inhibitory motifs (ITIMs), others have been shown to promote immune cell activation. ${ }^{69}$ Structurally, siglecs belong to the immunoglobulin superfamily and can be divided into two subsets: the less-related group (25-35\% identity), which includes sialoadhesin ( $\mathrm{Sn}$ : siglec-1), CD22 (siglec-2), and myelin-associated glycoprotein (MAG; siglec-4), and the rapidly-evolving group of CD33-related siglecs that share high sequence similarity (5090\%) (siglec-3, -5, -7, -8, -9, -10, -11, and -14 in humans and siglec-E, -F, -G, and -H in mice).$^{70}$ The latter GBPs are defined by their well-known carbohydrate specificity for sialic acid-containing glycans, and for their ability to discriminate among different linkages (a2-3, a2-6, and a2-8). ${ }^{71}$ These glycan structures can be found on immune cells, epithelial cells, and tumor cells. Interestingly, microbes may capture sialic acid from host cells, which prevents their immune recognition as foreign and enables infection of host target cells through specific recognition of siglecs. ${ }^{71}$ This is clearly exemplified by Campylobacter jejuni, Neisseria meningitides, and group B streptococci, which interact with CD33-related siglecs. ${ }^{72}$ Unique to this lectin family, siglecs can mediate cis and trans interactions with 
sialylated glycans. Although with cis interactions the siglec is often masked by low-affinity ligands on neighboring receptors, these linkages do not prevent trans interactions with other cell types. ${ }^{69}$

Although some siglecs have very restricted localization patterns, others are more widely expressed within hematopoietic cells. For example, $\mathrm{Sn}$ is preferentially expressed on macrophages, CD22 on B cells, and siglec- 8 on eosinophils. ${ }^{69}$ Interestingly, siglec- 9 and siglec-E are selectively expressed on human and mouse myeloid-derived DCs, respectively, while siglec-5 and siglec-H are expressed on human and mouse plasmacytoid DCs, respectively.$^{69}$ For most CD33-related siglecs, ligand engagement results in tyrosine phosphorylation of ITIMs by Src family tyrosine kinases and recruitment of Src homology 2 (SH2)-containing phosphatases (SHPs), such as SHP-1 and SHP-2, which control cellular activation by attenuating tyrosine phosphorylation. ${ }^{73}$ Recent work has identified siglec-10 in humans and siglec-G in mice as binding partners that recognize CD24 and discriminate between pathogen-associated and danger-associated molecular partners. ${ }^{74}$ Moreover, like CLRs, siglec-H has been identified as a specific endocytic receptor on plasmacytoid DCs that can take up viruses and other pathogens for delivery to intracellular TLRs and, ultimately, for induction of antiviral immunity ${ }^{75}$ In contrast to other members of the family, siglec-H lacks tyrosine-based signaling motifs and associates with the adaptor DAP-12 to exert its function. ${ }^{75}$ Thus, selective targeting of individual siglecs may serve to differentially shape immune cell signaling.

In contrast to C-type lectins and siglecs, which are mostly cell surface-associated receptors, galectins belong to a category of soluble immunomodulatory proteins that may act either intracellularly, by modulating signaling pathways, or extracellularly, as bioactive regulatory mediators. ${ }^{76}$ Galectins bind to $N$-acetyllactosamine (Gal $\beta 1,3 \mathrm{GlcNAc}$ or Gal $\beta 1,4 \mathrm{GlcNAc}$ ), a common disaccharide found on many $\mathrm{N}$ - and O-linked glycans present in different cellular counter-receptors and matricellular proteins ${ }^{25}$ (Fig. 1). Although galectins do not have the signal sequence required for the classical secretion pathway, most of them are secreted via a nonclassical export route that is still poorly understood. ${ }^{77}$ Traditionally, galectins are classified into prototype galectins (galectin-1, -2, -5, -7, -10, -11, -13, -14, -15), which have one CRD that can dimerize, tandem repeat galectins (galectin- $4,-6,-8,-9$ and -12 ), which contain two homologous CRDs in tandem in a single polypeptide chain, and the single member galectin-3, which is unique in that it contains a CRD connected to a non-lectin Nterminal region that is responsible for lectin oligomerization. ${ }^{78}$ Although some galectins have a wide tissue distribution (e.g., galectin-1 and -3), others have preferential localization, for example, galectin-7 in skin, galectin-12 in adipose tissue, and galectin-10 in eosinophils and regulatory T cells. ${ }^{77}$ Interestingly, galectin-3 and galectin- 9 play key roles as PRRs by discriminating Leishmania species to stimulate appropriate innate immune responses. ${ }^{78}$

Different factors can regulate the function of galectins, including (1) their dynamic expression during the development and resolution of innate and adaptive immune responses; (2) the programmed remodeling of cell surface glycans generated by the concerted action of glycosyltransferases; (3) their dimerization or oligomerization status; and (4) the stability of these proteins in oxidative or reducing microenvironments. ${ }^{77}$ Through their ability to recognize specific glycan structures, galectins are potential soluble mediators involved in immune cell communication, signaling, host-microbial interactions, $T$ helper cell homeostasis, preservation of fetomaternal tolerance, and suppression of autoimmune pathology. In addition, galectins may contribute to the creation of immunosuppressive microenvironments at sites of tumor growth and metastasis. ${ }^{25}$

Interestingly, accruing evidence from a number of laboratories indicates that $\mathrm{N}$ - and $\mathrm{O}$ glycosylation can modulate interactions of receptors and ligands themselves, thereby 
altering receptor endocytosis, clustering, and signaling. Lectins, particularly galectins, have been shown to play critical roles in these cellular processes through binding and crosslinking specific glycans attached to a preferred set of counter-receptors, thereby forming supramolecular interactions or lattices that fine-tune the dynamics of receptor-ligand interactions. ${ }^{12,79}$ This includes modulation of cytokine receptor signaling, $\mathrm{T}$ cell receptor (TCR)-mediated activation at sites of immunological synapse, and B cell receptor (BCR)integrin signaling during B cell maturation. ${ }^{12}$ However, galectins can also bind their ligands in a carbohydrate-independent manner, which is often the case for galectins localized in the intracellular compartment, where ligand binding occurs predominantly via protein-protein interactions. $^{25}$

Although the in vivo roles of endogenous galectins are just now emerging, recent studies have demonstrated distinctive immunological phenotypes in mice lacking individual members of the family. For example, mice lacking the gene for either galectin-1 or galectin- 9 show increased Th1 and Th17 responses and augmented inflammatory responses, ${ }^{80-82}$ whereas mice deficient in galectin-3 exhibit reduced inflammation in mouse models of multiple sclerosis and arthritis. ${ }^{83,84}$ Thus, in spite of protein sequence similarities, overlapping distribution, and functional redundancy, individual members of the galectin family may play distinct roles in the control of immune cell homeostasis. Moreover, different lectin families may overlap, synergize, and/or counter-regulate the effect of each other through recognition of a similar set of glycan ligands. Given their multifunctional properties and versatility, GBPs, including CLRs, siglecs, and galectins, are increasingly recognized as molecular targets for innovative drug discovery in immune-mediated disorders.

\section{Glycobiology of autoimmunity and chronic inflammation}

In spite of compelling evidence of the role of glycosylation in pathogen recognition, our awareness of the impact of lectin-glycan interactions in the control of immune tolerance, autoimmunity, and chronic inflammation is relatively new. These emerging data are based on pioneering observations demonstrating programmed remodeling of cell surface glycans in the transition from normal to inflamed tissues ${ }^{85}$ These changes affect emigration and trafficking of immune cells to sites of inflammation, as demonstrated for selectins that bind to sialylated and fucosylated epitopes (e.g., sLe ${ }^{\mathrm{x}}$ ) often found in sulphated form on glycans present on most leukocytes and endothelial cells. ${ }^{86}$ Thus, inhibition of selectins and glycans during leukocyte-endothelium interactions has been proposed as an attractive target for antiinflammatory therapy.

However, glycosylation can control inflammation and autoimmunity through modulation of other homeostatic checkpoints. In fact, in several inflammatory autoimmune diseases, such as systemic lupus erythematosus and rheumatoid arthritis, effector $\mathrm{T}$ cells express altered cell surface glycans, especially those exposing terminal GalNAc and Gal- $\beta(1-4)$-GlcNAc structures. ${ }^{87}$ For example, MGL and galectin interactions with these structures thereby downregulate TCR signaling and alter CD45 phosphatase activity. ${ }^{18,39,68}$ In addition, glycosylation can alter the threshold of TCR activation, which can have profound effects on $\mathrm{T}$ cell function during adaptive immunity and autoimmune diseases. The GnT5 glycosyltransferase, encoded by the mannoside acetylglucosaminyl transferase 5 (Mgat5) gene, initiates formation of the $\beta 1-6-N$-glycan-branch structure on various glycoproteins, including the TCR. This $N$-glycan branch typically includes $N$-acetyllactosamine (LacNAc; Fig. 1) disaccharide repeats that serve as ligands for galectins. T cells lacking GnT5 have a decreased threshold for T cell activation, and GnT5-deficient mice have increased delayedtype hypersensitivity responses and increased susceptibility to autoimmune diseases, including experimental autoimmune encephalomyelitis (EAE), glomerulonephritis, and 
immune complex deposition. ${ }^{18}$ Interestingly, treatment with high doses of GlcNAc was shown to increase GnT5-mediated $N$-glycan branching and inhibited TCR activation in autoimmune models of EAE and diabetes. ${ }^{88}$

Although these studies highlight the relevance of glycosylation in the control of adaptive immunity and the development of autoimmune diseases, other studies have been instrumental to understanding the contribution of innate immune mechanisms to autoimmune and inflammatory settings. Deficiency in a-mannosidase-II (aM-II), which results in diminished complex-type $\mathrm{N}$-glycan branching, has been shown to induce an autoimmune disease in mice similar to human systemic lupus erythematosus. ${ }^{89}$ This effect was independent of the adaptive immune system and was linked to chronic activation of innate immune components. The authors proposed a mechanism by which the exposure of cryptic $\mathrm{N}$-glycans under aM-II deficiency (i.e., mannose-dependent ligands) results in recognition by endogenous lectins (including MR) and aberrant activation of innate immune responses in the absence of infection, thus leading to the development of lupus-like autoimmune disease. ${ }^{89}$ Thus, selective targeting of glycan-modifying enzymes, early or late during $\mathrm{N}$-complex glycan branching, can result in aberrant activation of innate or adaptive immune responses.

However, it is not only $N$-glycans that influence the development and resolution of autoimmune response. In patients with IgA nephropathy, for example, $O$-glycans attached to IgA are truncated to expose GlcNAc, which correlates with antibody deposition in the inflamed kidney; ${ }^{90}$ this suggests that differential glycosylation of immunoglobulins critically regulates their biological functions. A striking example of this is the presence of a2,6 sialic acid in the Fc region of $\mathrm{IgG}$, which determines the anti-inflammatory function of IVIGs in several autoimmune diseases. ${ }^{26}$

Antibodies specific for glycans have been found in different settings. For example, because humans lack the enzyme that converts $N$-acetylneuraminic acid (NeuAc) to $N$ glycolylneuraminic acid (NeuGc), incorporation of NeuGc in the diet can lead to the generation of antibodies against NeuGc. ${ }^{91}$ In addition, antibodies specific for particular glycans have also been found in the human Tn syndrome, which is characterized by thrombocytopenia and leukocytopenia and caused by a mutation in the COSMC gene encoding a chaperone required for $\beta 1,3$ galactosyltransferase (T-synthase) activity required for $O$-glycan biosynthesis. ${ }^{92}$

The biological roles for the different repertoires of cell surface glycans found on different immune cell types are just emerging. For example, a2,6-linked sialic acid is selectively upregulated on the surface of Th2 but not Th1 and Th17 effector cells, and this difference determines the susceptibility of these $\mathrm{T}$ cell subsets to the GBP galectin- $1 .{ }^{80}$ Accordingly, galectin-1-deficient $\left(\mathrm{Lgalsl}^{-/-}\right)$mice develop more severe autoimmune manifestations during EAE due to selective expansion of antigen-specific Th1 and Th17 cells and to increased immunogenicity of DCs. ${ }^{80,93}$ Therapeutic administration of recombinant galectin-1 has been shown to restore tolerance and suppress chronic inflammation in several experimental models of autoimmunity (arthritis, uveitis, EAE, hepatitis, diabetes, and inflammatory bowel disease); to prevent fetal loss; and to attenuate graft-versus-host disease by suppressing Th1 and Th17 responses, by expanding regulatory T cell populations, and by fueling tolerogenic DC circuits (reviewed in Ref. 76). These effects were also observed following administration of the tandem-repeat galectin-9, which suppresses harmful autoimmune responses through its ability to bind the Tim-3 glycoreceptor. ${ }^{81}$

C-type lectins can also play important roles in the modulation of inflammatory and autoimmune diseases. In vivo targeting of a mannosylated encephalitogenic peptide has been 
shown to inhibit the onset of EAE, most likely by targeting the mannose receptor on immature DCs. ${ }^{94}$ Similarly, oral administration of mannose-enriched antigens can induce oral tolerance and favor the generation of IL-10-producing regulatory $\mathrm{T}(\mathrm{Tr} 1)$ cells through mechanisms involving the CLR SIGNR1 expressed on lamina propria DCs. ${ }^{95}$ Moreover, siglec-2 (CD22) delivers inhibitory signals to B cells, and siglec-G/CD22 double knockout mice spontaneously develop B cell-dependent autoimmunity characterized by the presence of anti-DNA and antinuclear autoantibodies. ${ }^{96}$ These data suggest that different GBPs may amplify or silence tolerogenic circuits within DC, T cell, or B cell compartments.

\section{Glycobiology of tumor immunity}

Changes in the glycosylation status of certain tumor-associated antigens (TAAs) are often accompanied by onco-transformation. Such TAAs include the CEA and MUC1. ${ }^{62,63}$ Both antigens are expressed on cells of normal colonic mucosa and the epithelium. Changes in glycosylation include increased expression of the Lewis blood group family of antigens, particularly $\mathrm{Le}^{\mathrm{x}}$ and $\mathrm{Le}^{\mathrm{y}}$, that are often associated with poor prognosis of the tumor. How these posttranslational modifications contribute to tumor cell dissemination and disease severity is not fully understood. However, recent findings demonstrate that DCs recognize these aberrantly glycosylated structures on CEA or MUC1 through CLRs, such as DC-SIGN and MGL, respectively, while these CLRs do not interact with normal CEA or MUC1 from colon tissue. 97

Several studies have demonstrated that specific targeting of antigens to CLRs can result in more robust antitumor responses. An elegant study demonstrated that in vivo targeting of CLRs in the mouse can induce antigen-specific autoimmune responses when the antigen is coupled to a DEC-205-specific antibody. ${ }^{98}$ In contrast, when the antigen coupled to DEC-205-Ab is simultaneously combined with a strong DC activator, such as a TLR agonist, a strong antigen-specific immune activation is induced that results in potentiation of antitumor responses and, ultimately, eradication of the tumor. Moreover, other CLRs have also been used for targeting purposes resulting in strong induction of immunity. ${ }^{99-101}$

CLEC9A is a CLR predominantly expressed on a subset of DCs in human and mice that functions to promote phagocytosis of dead cells for MHC class I-dependent crosspresentation and stimulation of $\mathrm{CD}^{+} \mathrm{T}$ cell responses. The precise ligand recognized by CLEC9A on dead cells has not yet been identified, and it is under debate whether CLEC9A ultimately recognizes glycan structures or protein frameworks. The targeting of antigen to CLEC9A, using antibody-antigen conjugates, has led to the efficient endocytosis of antigen and to enhanced $\mathrm{CD}^{+}{ }^{+}$and $\mathrm{CD}^{+} \mathrm{T}$ cell proliferation and more robust antibody responses. Furthermore, targeting of CLEC9A in cancer cells in mouse models has been shown to heighten T cell-mediated tumor rejection. ${ }^{4,102}$ In addition, another strategy to target antigen to CLRs on DCs involves using natural ligands (glycan structures) to modify antigen. ${ }^{103}$ The use of glycans for in vivo DC-targeting purposes has advantages over CLRspecific antibodies because glycans, which are nonimmunogenic and of self-origin, can be produced synthetically to large scale using simple chemistry. ${ }^{104}$ In contrast, the production of humanized antibodies is expensive, and such antibodies can be immunogenic in patients. Furthermore, antibodies themselves are highly glycosylated, a property that is currently being capitalized on to increase or decrease their therapeutic potential in vivo.

Modification of the melanoma antigen gp100 with high mannose has been demonstrated to enhance both gp100-specific $\mathrm{CD}^{+}$and $\mathrm{CD}^{+} \mathrm{T}$ cell responses, because high-mannose structures target DC-SIGN on DCs and this leads to enhanced endosomal-dependent antigen presentation. ${ }^{55}$ Ovalbumin (OVA) modified with fucose-containing Lewis ${ }^{\mathrm{b}}$ structures not only improved targeting of OVA to DC-SIGN, as shown by enhanced antigen uptake by 
DCs from DC-SIGN transgenic mice, but also increased cross-presentation to OVA-specific $\mathrm{CD}^{+}$and $\mathrm{CD} 4^{+} \mathrm{T}$ cells. ${ }^{44}$ Moreover, two other MR-specific ligands, sulfo Lewis ${ }^{\mathrm{A}}$ or GlcNAc, significantly enhanced targeting of OVA to the MR when they were ligated to OVA, thereby increasing cross-presentation of OVA to OT-I (OVA-specific) T cells in vitro. ${ }^{100}$ Interestingly, in both studies using the natural ligands to target antigen to CLR, cross-presentation was increased in the absence of DC maturation signals. Improvement in $\mathrm{CD}^{+}$and $\mathrm{CD} 8^{+} \mathrm{T}$ cell priming has been demonstrated not only by modification of antigens with glycans; glycosylated nanoparticles have also been designed that specifically target DCs to improve antigen-specific immune responses. In addition, CLRs are currently being used to enhance delivery of several vaccines to DCs, as well as to improve CD4 ${ }^{+}$and CD8 ${ }^{+}$ $T$ cell priming, due to the high efficacy of CLRs to promote antigen processing in these APCs.

Emerging evidence indicates that tumors may exploit lectin-glycan interactions to evade immune responses. ${ }^{105}$ Galectin- 1 secreted by tumor cells contributes to the immunosuppressive potential of different tumor types, including melanoma, ${ }^{106,107}$ Hodgkin's lymphoma, ${ }^{108}$ lung carcinoma, ${ }^{109,110}$ pancreatic carcinoma, ${ }^{111}$ and neuroblastoma, ${ }^{112}$ by selectively modulating $\mathrm{T}$ cell and $\mathrm{DC}$ compartments. The mechanisms underlying this immunoregulatory effect involve a bias toward a Th2-dominant cytokine profile and activation of tolerogenic circuits mediated by IL-27-producing DCs and IL-10producing type $1 \mathrm{~T}$ regulatory ( $\mathrm{Tr} 1)$ cells. ${ }^{93,110}$ Moreover, overexpression of galectin-9 results in increased frequency of $\mathrm{CD} 11 \mathrm{~b}^{+} \mathrm{Ly}-6 \mathrm{G}^{+}$granulocytic myeloid suppressor cells and inhibition of antitumor responses, ${ }^{113}$ while the presence of galectin- 3 appears to control the anergic state of T cells. ${ }^{114}$ Thus, selective inhibition of individual members of the galectin family may contribute to circumventing immunosuppression at sites of tumor growth by targeting distinct immunoevasive programs.

Recent work has demonstrated a novel glycosylation-dependent mechanism of tumorimmune escape. Bladder tumor cells overexpressing the core- $2 \beta-1,6-N$ -

acetylglucosaminyltransferase (GCNT1 encoded by $C 2 G n T$ ), which is responsible for elongating core-2 $O$-glycans (i.e., $O$-glycans containing a GlcNAc branch connected to GalNAc; Fig. 1), are highly metastatic due to their ability to evade NK cell immunity. The recent data suggest that interactions between poly-LacNAc residues present on core- $2 \mathrm{O}$ glycans of tumor-associated MHC class I-related chain A (MICA) and galectin-3 reduced the affinity of MICA for the activating NK receptor NKG2D, thereby impairing NK cell activation and antitumor activity. ${ }^{15}$ Similarly, expression of the ganglioside GD3 by tumor cells can also alter NK cell cytotoxicity via siglec-7-dependent mechanisms. ${ }^{116}$ Moreover, mucins derived from human cancer patients can control the immunogenicity of DCs through mechanisms involving siglec-9. ${ }^{117}$

Collectively, these data indicate that, in addition to differential gene and protein expression profiles, the lectin repertoire, as well as the cellular glycosylation signatures prevailing in the tumor microenvironment, may provide distinctive cellular codes that influence immune cell fate and cancer progression.

\section{Conclusions}

In this issue of Annals of the New York Academy of Sciences, reviews are presented on the multifaceted and often unexpected roles played by carbohydrates within the immune system. These include how sialic acids control immunity; the impact of glycans and glycosylation on cancer, autoimmunity, and lymphocyte development; and the role of carbohydrates on host and microbe during infection. This brief introduction highlights some of the bestcharacterized areas of glycan-focused immunology research, with the goal of illustrating the 
fact that carbohydrates are as integral to immune pathways as are proteins and lipids. The field of glycoimmunology is just beginning to find solid grounding through improved and more accessible carbohydrate-specific analytical tools. We hope the reviews presented in this special issue will encourage the immunology community to take notice of myriad unanswered questions on how carbohydrates influence immune responses. Deep investigation of these questions will surely lead to a greater understanding of the function of the immune system, and eventually of biology as a whole.

\section{Acknowledgments}

Work in G.A.R.'s lab is supported by Grants from the National Agency for the Promotion of Science and Technology of Argentina (PICT 2010-870), the University of Buenos Aires, the Mizutani Foundation for Glycoscience (Japan), the National Multiple Sclerosis Society (U.S.A.), Fundación Sales, and Prostate Action (U.K.). Work in Y.v.K.'s lab is supported by grants from the Dutch Cancer Foundation (KWF), the Dutch Society for MS research, the Netherlands Organisation for Scientific Research (NWO), Agentschap NL, and the VUmc Institute for Cancer and Immunology. Work in B.A.C.'s lab is supported by Grants from the National Institute of Allergy and Infectious Diseases (AI079756), the National Institute of General Medical Sciences (GM082916), the National Institutes of Health, Office of the Director (OD004225), the American Asthma Foundation, and the Chronic Granulomatous Disorder Research Trust. We thank M.A. Toscano for help in figure illustration.

\section{References}

1. Levine MJ, Reddy MS, Tabak LA, et al. Structural aspects of salivary glycoproteins. J Dent Res. 1987; 66:436-441. [PubMed: 3305626]

2. Brockhausen, I.; Schachter, H.; Stanley, P. O-GalNAc Glycans. In: Varki, A.; Cummings, RD.; Esko, JD.; Freeze, HH.; Stanley, P.; Bertozzi, CR.; Hart, GW.; Etzler, ME., editors. Essentials of Glycobiology. Cold Spring Harbor: Cold Spring Harbor Laboratory Press; 2009. p. 115-127.

3. Stanley, P.; Schachter, H.; Taniguchi, N. N-Glycans. In: Varki, A.; Cummings, RD.; Esko, JD.; Freeze, HH.; Stanley, P.; Bertozzi, CR.; Hart, GW.; Etzler, ME., editors. Essentials of Glycobiology. Cold Spring Harbor: Cold Spring Harbor Laboratory Press; 2009. p. 101-114.

4. Nothaft H, Szymanski CM. Protein glycosylation in bacteria: sweeter than ever. Nat Rev Microbiol. 2010; 8:765-778. [PubMed: 20948550]

5. Theodore M, Morava E. Congenital disorders of glycosylation: sweet news. Curr Opin Pediatr. 2011; 23:581-587. [PubMed: 21970833]

6. Van Geet C, Jaeken J, Freson K, et al. Congenital disorders of glycosylation type Ia and IIa are associated with different primary haemostatic complications. J Inherit Metab Dis. 2001; 24:477492. [PubMed: 11596651]

7. Wang Y, Tan J, Sutton-Smith M, et al. Modeling human congenital disorder of glycosylation type IIa in the mouse: conservation of asparagine-linked glycan-dependent functions in mammalian physiology and insights into disease pathogenesis. Glycobiology. 2001; 11:1051-1070. [PubMed: 11805078]

8. Ohtsubo K, Marth JD. Glycosylation in cellular mechanisms of health and disease. Cell. 2006; 126:855-866. [PubMed: 16959566]

9. Takahashi M, Kuroki Y, Ohtsubo K, Taniguchi N. Core fucose and bisecting GlcNAc, the direct modifiers of the $N$-glycan core: their functions and target proteins. Carbohydr Res. 2009; 344:13871390. [PubMed: 19508951]

10. Oberg F, Sjohamn J, Fischer G, et al. Glycosylation increases the thermostability of human aquaporin 10 protein. J Biol Chem. 2011; 286:31915-31923. [PubMed: 21733844]

11. Garner OB, Baum LG. Galectinglycan lattices regulate cell-surface glycoprotein organization and signalling. Biochem Soc Trans. 2008; 36:1472-1477. [PubMed: 19021578]

12. Boscher C, Dennis JW, Nabi IR. Glycosylation, galectins and cellular signaling. Curr Opin Cell Biol. 2011; 23:383-392. [PubMed: 21616652]

13. Li Y, Li H, Dimasi N, et al. Crystal structure of a superantigen bound to the high-affinity, zincdependent site on MHC class II. Immunity. 2001; 14:93-104. [PubMed: 11163233] 
14. Dai S, Murphy GA, Crawford F, et al. Crystal structure of HLA-DP2 and implications for chronic beryllium disease. Proc Natl Acad Sci USA. 2010; 107:7425-7430. [PubMed: 20356827]

15. Harrison RL, Jarvis DL. Protein $N$-glycosylation in the baculovirus-insect cell expression system and engineering of insect cells to produce "mammalianized" recombinant glycoproteins. Adv Virus Res. 2006; 68:159-191. [PubMed: 16997012]

16. Blixt O, Head S, Mondala T, et al. Printed covalent glycan array for ligand profiling of diverse glycan binding proteins. Proc Natl Acad Sci USA. 2004; 101:17033-17038. [PubMed: 15563589]

17. Comelli EM, Head SR, Gilmartin T, et al. A focused microarray approach to functional glycomics: transcriptional regulation of the glycome. Glycobiology. 2006; 16:117-131. [PubMed: 16237199]

18. Demetriou M, Granovsky M, Quaggin S, Dennis JW. Negative regulation of T-cell activation and autoimmunity by Mgat5 N-glycosylation. Nature. 2001; 409:733-739. [PubMed: 11217864]

19. Ryan SO, Bonomo JA, Zhao F, Cobb BA. MHCII glycosylation modulates Bacteroides fragilis carbohydrate antigen presentation. J Exp Med. 2011; 208:1041-1053. [PubMed: 21502329]

20. Amith SR, Jayanth P, Franchuk S, et al. Dependence of pathogen molecule-induced toll-like receptor activation and cell function on Neu1 sialidase. Glycoconj J. 2009; 26:1197-1212. [PubMed: 19430901]

21. Amith SR, Jayanth P, Franchuk S, et al. Neu1 desialylation of sialyl alpha-2,3-linked betagalactosyl residues of TOLL-like receptor 4 is essential for receptor activation and cellular signaling. Cell Signal. 2010; 22:314-324. [PubMed: 19796680]

22. van Kooyk Y, Geijtenbeek TB. DC-SIGN: escape mechanism for pathogens. Nat Rev Immunol. 2003; 3:697-709. [PubMed: 12949494]

23. Andersson KB, Draves KE, Magaletti DM, et al. Characterization of the expression and gene promoter of CD22 in murine B cells. Eur J Immunol. 1996; 26:3170-3178. [PubMed: 8977319]

24. O'Reilly MK, Tian H, Paulson JC. CD22 is a recycling receptor that can shuttle cargo between the cell surface and endosomal compartments of B cells. J Immunol. 2011; 186:1554-1563. [PubMed: 21178016]

25. Liu FT, Rabinovich GA. Galectins: regulators of acute and chronic inflammation. Ann N Y Acad Sci. 2010; 1183:158-182. [PubMed: 20146714]

26. Anthony RM, Kobayashi T, Wermeling F, Ravetch JV. Intravenous gammaglobulin suppresses inflammation through a novel TH2 pathway. Nature. 2011; 475:110-113. [PubMed: 21685887]

27. Kaneko Y, Nimmerjahn F, Ravetch JV. Anti-inflammatory activity of immunoglobulin G resulting from Fc sialylation. Science. 2006; 313:670-673. [PubMed: 16888140]

28. Matsushita M. Ficolins: complement-activating lectins involved in innate immunity. J Innate Immun. 2010; 2:24-32. [PubMed: 20375620]

29. Stanley P, Okajima T. Roles of glycosylation in Notch signaling. Curr Top Dev Biol. 2010; 92:131-164. [PubMed: 20816394]

30. Lowe JB. Glycan-dependent leukocyte adhesion and recruitment in inflammation. Curr Opin Cell Biol. 2003; 15:531-538. [PubMed: 14519387]

31. Mitoma J, Bao X, Petryanik B, et al. Critical functions of N-glycans in L-selectin-mediated lymphocyte homing and recruitment. Nat Immunol. 2007; 8:409-418. [PubMed: 17334369]

32. Pashov A, Garimalla S, Monzavi-Karbassi B, Kieber-Emmons T. Carbohydrate targets in HIV vaccine research: lessons from failures. Immunotherapy. 2009; 1:777-794. [PubMed: 20636023]

33. Krinos CM, Coyne MJ, Weinacht KG, et al. Extensive surface diversity of a commensal microorganism by multiple DNA inversions. Nature. 2001; 414:555-558. [PubMed: 11734857]

34. Carlin AF, Lewis AL, Varki A, Nizet V. Group B streptococcal capsular sialic acids interact with siglecs (immunoglobulin-like lectins) on human leukocytes. J Bacteriol. 2007; 189:1231-1237. [PubMed: 16997964]

35. van Kooyk Y, Rabinovich GA. Protein-glycan interactions in the control of innate and adaptive immune responses. Nat Immunol. 2008; 9:593-601. [PubMed: 18490910]

36. Drickamer K. C-type lectin-like domains. Curr Opin Struct Biol. 1999; 9:585-590. [PubMed: 10508765]

37. Figdor CG, van Kooyk Y, Adema GJ. C-type lectin receptors on dendritic cells and Langerhans cells. Nat Rev Immunol. 2002; 2:77-84. [PubMed: 11910898] 
38. Kawasaki T, Li M, Kozutsumi Y, Yamashina I. Isolation and characterization of a receptor lectin specific for galactose/ $N$-acetylgalactosamine from macrophages. Carbohydr Res. 1986; 151:197206. [PubMed: 3768888]

39. van Vliet SJ, Saeland E, van Kooyk Y. Sweet preferences of MGL:carbohydrate specificity and function. Trends Immunol. 2008; 29:83-90. [PubMed: 18249034]

40. Zelensky AN, Gready JE. The C-type lectin-like domain superfamily. FEBS J. 2005; 272:61796217. [PubMed: 16336259]

41. Engering A, Geijtenbeek TB, van Vliet SJ, et al. The dendritic cell-specific adhesion receptor DCSIGN internalizes antigen for presentation to T cells. J Immunol. 2002; 168:2118-26. [PubMed: 11859097]

42. Unger WWJ, van Kooyk Y. Dressed for success; C-type lectin receptors for the delivery of glycovaccines to dendritic cells. Curr Opin Immunol. 2011; 23:131-137. [PubMed: 21169001]

43. Birkholz K, Schwenkert M, Kellner C, et al. Targeting of DEC-205 on human dendritic cells results in efficient MHC class II-restricted antigen presentation. Blood. 2010; 116:2277-2285. [PubMed: 20566893]

44. Singh SK, Stephani J, Schaefer M, et al. Targeting of glycan modified OVA to murine DC-SIGN transgenic dendritic cells enhances MHC class I and II presentation. Mol Immunol. 2009a; 47:164-174. [PubMed: 19818504]

45. Idoyaga J, Cheong C, Suda K, et al. Langerin/CD207 receptor on dendritic cells mediates efficiënt antigen presentation of non MHC I and II products in vivo. J Immunol. 2008; 180:3647-3650. [PubMed: 18322168]

46. Bozzacco L, Trumpfheller C, Siegal FP, et al. DEC-205 receptor on dendritic cells mediates presentation of HIV gag protein to CD8+ T cells in a spectrum of human MHC I haplotypes. Proc Natl Acad Sci USA. 2007; 104:1289-1294. [PubMed: 17229838]

47. Sancho D, Mourao-Sa D, Joffre OP, et al. Tumor therapy in mice via antigen targeting to a novel DC restricted C-type lectin. J Clin Invest. 2008; 118:2098-2110. [PubMed: 18497879]

48. Osorio F, Reis e Sousa C. Myeloid C-type lectin receptors in pathogen recognition and host defense. Immunity. 2011; 34:651-664. [PubMed: 21616435]

49. Park CG, Takahara K, Umemoto E, et al. Five mouse homologues of the human dendritic cell Ctype lectin, DC-SIGN. Int Immunol. 2001; 13:1283-1290. [PubMed: 11581173]

50. Singh SK, Streng-Ouwehand I, Litjens M, et al. Characterization of murine MGL 1 and MGL 2 Ctype lectins: Distinct glycan specificities and tumor binding properties. Mol immunol. 2009b; 46:1240-1249. [PubMed: 19162326]

51. Denda-Nagai K, Aida S, Saba K, et al. Distribution and function of macrophage galactose-type Ctype lectin 2 (MGL2/CD301b): efficient uptake and presentation of glycosylated antigens by dendritic cells. J Biol Chem. 2010; 285:19193-19204. [PubMed: 20304916]

52. Brown GD. Dectin-1: a signaling non-TLR pattern-recognition receptor. Nat Rev Immunol. 2006; 6:33-43. [PubMed: 16341139]

53. Van Die I, Cummings RD. Glycan mimmickry by parasitic helminths: a strategy for modulating the host immune response? Glycobiology. 2010; 20:2-12. [PubMed: 19748975]

54. Gow NAR, van de Veerdonk FL, Brown AJP, Netea MG. Candida albicans morphogenesis and host defense: discriminating invasion from colonization. Nat Rev Microbiol. 2012; 10:112-122. [PubMed: 22158429]

55. Aarnoudse CA, Bax M, Sánchez-Hernández M, et al. Glycan modification of the tumor antigen gp100 targets DC-SIGN to enhance dendritic cell induced antigen presentation to T cells. Int J Cancer. 2008; 122:839-46. [PubMed: 17957800]

56. Gringhuis SI, van Dunnen J, Litjens M, et al. C-type lectin DC-SIGN modulates Toll-like receptor signaling via Raf-1 kinase-dependent acetylation of transcription factor NF-kappaB. Immunity. 2007; 26:605-616. [PubMed: 17462920]

57. Gringhuis SI, den Dunnen J, Litjens M, et al. Carbohydrate-specific signalling through the DCSIGN signalosome tailors immunity to Mycobacterium tuberculosis, HIV-1 and Helicobacter pylori. Nat Immunol. 2009; 10:1081-1088. [PubMed: 19718030]

58. Geijtenbeek TB, Gringhuis SI. Signalling through C-type lectin receptors: shaping immune responses. Nat Rev Immunol. 2009; 9:465-479. [PubMed: 19521399] 
59. Geijtenbeek TBH, van Vliet SJ, Engering A, et al. Self- and non-self recognition by C-type lectins on dendritic cells. Ann Rev Immunol. 2003; 22:33-54. [PubMed: 15032573]

60. Dam TK, Brewer CF. Lectins as pattern recognition molecules: the effects of epitope density in innate immunity. Glycobiology. 2010; 20:270-279. [PubMed: 19939826]

61. van Gisbergen KPJM, Aarnoudse CA, Meijer GA, et al. Dendritic cells recognize tumor-specific glycosylation of carcinoembryonic antigen on colorectal cancer cells through dendritic cellspecific intercellular adhesion molecule-3-grabbing nonintegrin. Cancer Res. 2005a; 65:59355943. [PubMed: 15994972]

62. Saeland E, van Vliet SJ, Bäckström M, et al. The C-type lectin MGL expressed by dendritic cells detects glycan changes on MUC1 in colon carcinoma. Cancer Immunol Immunother. 2007; 56:1225-1236. [PubMed: 17195076]

63. Geijtenbeek TBH, Kwon DS, Torensma R, et al. DC-SIGN, a dendritic cell specific HIV-1 binding protein that enhances trans-infection of T cells. Cell. 2000; 100:587-597. [PubMed: 10721995]

64. de Witte L, Nabatov A, Prion M, et al. Langerin is a natural barrier to HIV-1 transmission by Langerhans cells. Nat Med. 2007; 13:367-371. [PubMed: 17334373]

65. Lambert AA, Gilbert C, Richard M, et al. The C-type lectin surface receptor DCIR acts as a new attachment factor for HIV-1 in dendritic cells and contributes to trans-and cis-infection pathways. Blood. 2008; 112:1299-1307. [PubMed: 18541725]

66. Garcia-Vallejo JJ, van Kooyk Y. Endogenous ligands for C-type lectin receptors: the true regulators of immune homeostatis. Immunol Rev. 2009; 230:22-37. [PubMed: 19594627]

67. van Gisbergen KPJM, Sanchez-Hernandez M, Geijtenbeek TB, van Kooyk Y. Neutrophils mediate immune modulation of dendritic cells through glycosylation-dependent interactions between Mac-1 and DC-SIGN. J Exp Med. 2005b; 201:1281-1292. [PubMed: 15837813]

68. van Vliet SJ, Gringhuis SI, Geijtenbeek TB, van Kooyk Y. Regulation of effector T cells by antigen-presenting cells via interaction of the C-type lectin MGL with CD45. Nat Immunol. 2006; 24:1200-1208. [PubMed: 16998493]

69. Crocker PR, Paulson JC, Varki A. Siglecs and their roles in the immune system. Nat Rev Immunol. 2007; 7:255-266. [PubMed: 17380156]

70. O'Reilly MK, Paulson JC. Siglecs as targets for therapy in immune-cell-mediated disease. Trends Pharmacol Sci. 2009; 30:240-248. [PubMed: 19359050]

71. Angata T, Varki A. Chemical diversity in the sialic acids and related alpha-keto acids: an evolutionary perspective. Chem Rev. 2002; 102:439-469. [PubMed: 11841250]

72. Avril T, Wagner ER, Willison HJ, Crocker PR. Sialic acid-binding immunoglobulin-like lectin 7 mediates selective recognition of sialylated glycans expressed on Campylobacter jejuni lipooligosaccharides. Infect Immun. 2006; 74:4133-4141. [PubMed: 16790787]

73. Paul SP, Taylor LS, Stansbury EK, McVicar DW. Myeloid specific human CD33 is an inhibitory receptor with differential ITIM function in recruiting the phosphatases SHP-1 and SHP-2. Blood. 2000; 96:483-490. [PubMed: 10887109]

74. Liu Y, Chen GY, Zheng P. CD24-Siglec G/10 discriminates danger- from pathogen-associated molecular patterns. Trends Immunol. 2009; 30:557-561. [PubMed: 19786366]

75. Blasius AL, Colonna M. Sampling and signaling in plasmacytoid dendritic cells: the potential roles of Siglec-H. Trends Immunol. 2006; 27:255-260. [PubMed: 16679063]

76. Rabinovich GA, Toscano MA. Turning 'sweet' on immunity: galectin-glycan interactions in immune tolerance and inflammation. Nat Rev Immunol. 2009; 9:338-352. [PubMed: 19365409]

77. Di Lella S, Sundblad V, Cerliani JP, et al. When galectins recognize glycans: from biochemistry to physiology and back again. Biochemistry. 2011; 50:7842-7857. [PubMed: 21848324]

78. Sato S, St-Pierre C, Bhaumik P, Nieminen J. Galectins in innate immunity: dual functions of host soluble beta-galactoside-binding lectins as damage-associated molecular patterns (DAMPs) and as receptors for pathogen-associated molecular patterns (PAMPs). Immunol Rev. 2009; 230:172187. [PubMed: 19594636]

79. Brewer CF, Miceli MC, Baum LG. Clusters, bundles, arrays and lattices: novel mechanisms for lectin-saccharide-mediated cellular interactions. Curr Opin Struct Biol. 2002; 12:616-623. [PubMed: 12464313] 
80. Toscano MA, Bianco GA, Ilarregui JM, et al. Differential glycosylation of TH1, TH2 and TH-17 effector cells selectively regulates susceptibility to cell death. Nat Immunol. 2007; 8:825-834. [PubMed: 17589510]

81. Zhu C, Anderson AC, Schubart A, et al. The Tim-3 ligand galectin-9 negatively regulates T helper type 1 immunity. Nat Immunol. 2005; 6:1245-1252. [PubMed: 16286920]

82. Cooper D, Ilarregui JM, Pesoa SA, et al. Multiple functional targets of the immunoregulatory activity of galectin-1: control of immune cell trafficking, dendritic cell physiology, and T-cell fate. Methods Enzymol. 2010; 480:199-244. [PubMed: 20816212]

83. Jiang HR, Al Rasebi Z, Mensah-Brown E, et al. Galectin-3 deficiency reduces the severity of experimental autoimmune encephalomyelitis. J Immunol. 2009; 182:1167-1173. [PubMed: 19124760]

84. Forsman H, Islander U, Andréasson E, et al. Galectin 3 aggravates joint inflammation and destruction in antigen-induced arthritis. Arthritis Rheum. 2011; 63:445-454. [PubMed: 21280000]

85. Dube DH, Bertozzi CR. Glycans in cancer and inflammation-potential for therapeutics and diagnostics. Nat Rev Drug Discov. 2005; 4:477-488. [PubMed: 15931257]

86. Sperandio M, Gleissner CA, Ley K. Glycosylation in immune cell trafficking. Immunol Rev. 2009; 230:97-113. [PubMed: 19594631]

87. Buzás EI, Gÿorgy B, Pásztói M, et al. Carbohydrate recognition systems in autoimmunity. Autoimmunity. 2006; 39:691-704. [PubMed: 17178566]

88. Grigorian A, Araujo L, Naidu NN, et al. N-acetylglucosamine inhibits T-helper 1 (Th1)/T-helper 17 (Th17) cell responses and treats experimental autoimmune encephalomyelitis. J Biol Chem. 2011; 286:40133-40141. [PubMed: 21965673]

89. Green RS, Stone EL, Tenno M, et al. Mammalian $N$-glycan branching protects against innate immune self-recognition and inflammation in autoimmune disease pathogenesis. Immunity. 2007; 27:308-320. [PubMed: 17681821]

90. Hiki Y, Odani H, Takahashi M, et al. Mass spectrometry proves under- $O$-glycosylation of glomerular IgA1 in IgA nephropathy. Kidney Int. 2001; 59:1077-1085. [PubMed: 11231363]

91. Padler-Karavani V, Yu H, Cao H, et al. Diversity in specificity, abundance, and composition of anti-Neu5Gc antibodies in normal humans: potential implications for disease. Glycobiology. 2008; 18:818-830. [PubMed: 18669916]

92. Ju T, Cummings RD. Protein glycosylation: chaperone mutation in Tn syndrome. Nature. 2005; 437:1252. [PubMed: 16251947]

93. Ilarregui JM, Croci DO, Bianco GA, et al. Tolerogenic signals delivered by dendritic cells to T cells through a galectin-1-driven immunoregulatory circuit involving interleukin 27 and interleukin 10. Nat Immunol. 2009; 10:981-991. [PubMed: 19668220]

94. Kel J, Oldenampsen J, Luca M, et al. Soluble mannosylated myelin peptide inhibits the encephalitogenicity of autoreactive T cells during experimental autoimmune encephalomyelitis. Am J Pathol. 2007; 170:272-280. [PubMed: 17200200]

95. Zhou Y, Kawasaki H, Hsu SC, et al. Oral tolerance to food-induced systemic anaphylaxis mediated by the C-type lectin SIGNR1. Nat Med. 2010; 16:1128-1133. [PubMed: 20835248]

96. Jellusova J, Wellmann U, Amann K, et al. CD22 x Siglec-G double-deficient mice have massively increased B1 cell numbers and develop systemic autoimmunity. J Immunol. 2010; 184:3618-3627. [PubMed: 20200274]

97. Saeland E, Belo AI, Mongera S, et al. Differential glycosylation of MUC1 and CEACAM5 between normal mucosa and tumour tissue of colon cancer patients. Int J Cancer. 2011 Aug 5. Epub ahead of print. 10.1002/ijc.26354

98. Bozzacco L, Trumpfheller C, Huang Y, et al. HIV gag protein is efficiently cross-presented when targeted with an antibody towards the DEC-205 receptor in Flt3 ligand-mobilized murine DC. Eur J Immunol. 2010; 40:36-46. [PubMed: 19830741]

99. Klechevsky E, Flamar AL, Cao Y, et al. Cross-priming CD8+ T cells by targeting antigens to human dendritic cells through DCIR. Blood. 2010; 116:1685-1697. [PubMed: 20530286]

100. Singh SK, Streng-Ouwehand I, Litjens M, et al. Design of neo-glycoconjugates that target the Mannose Receptor and enhance TLR independent cross-presentation and Th1 polarization. Eur J Immunol. 2011; 41:916-25. [PubMed: 21400496] 
101. Burgdorf S, Lukacs-Kornek V, Kurtc C. The man-nose receptor mediates uptake of soluble but not of cell-associated antigen for cross-presentation. J Immunol. 2006; 176:6770-6776. [PubMed: 16709836]

102. Caminischi I, Proietto AI, Ahmet F, et al. The dendritic cell subtype-restricted C-type lectin Clec9A is a target for vaccine enhancement. Blood. 2008; 112:3264-3273. [PubMed: 18669894]

103. Sánchez-Navarro M, Rojo J. Targeting DC-SIGN with carbohydrate multivalent systems. Drug News Perspect. 2010; 23:557-572. [PubMed: 21152451]

104. Streng-Ouwehand I, Unger WWJ, van Kooyk Y. C-type lectin receptors for tumor eradication: future directions. Cancers. 2011; 3:3169-3188. [PubMed: 24212951]

105. Salatino M, Rabinovich GA. Fine-tuning antitumor responses through the control of galectinglycan interactions: an overview. Methods Mol Biol. 2011; 677:355-374. [PubMed: 20941621]

106. Rubinstein N, Alvarez M, Zwirner NW, et al. Targeted inhibition of galectin-1 gene expression in tumor cells results in heightened $\mathrm{T}$ cell-mediated rejection; A potential mechanism of tumorimmune privilege. Cancer Cell. 2004; 5:241-251. [PubMed: 15050916]

107. Cedeno-Laurent F, Opperman MJ, Barthel SR, et al. Metabolic inhibition of galectin-1-binding carbohydrates accentuates antitumor immunity. J Invest Dermatol. 2012; 132:410-420. [PubMed: 22158550]

108. Juszczynski P, Ouyang J, Monti S, et al. The AP1-dependent secretion of galectin-1 by Reed Sternberg cells fosters immune privilege in classical Hodgkin lymphoma. Proc Natl Acad Sci USA. 2007; 104:13134-13139. [PubMed: 17670934]

109. Banh A, Zhang J, Cao H, et al. Tumor galectin-1 mediates tumor growth and metastasis through regulation of T-cell apoptosis. Cancer Res. 2011; 71:4423-4431. [PubMed: 21546572]

110. Kuo PL, Hung JY, Huang SK, et al. Lung cancer-derived galectin-1 mediates dendritic cell anergy through inhibitor of DNA binding 3/IL-10 signaling pathway. J Immunol. 2011; 186:1521-1530. [PubMed: 21191065]

111. Tang D, Yuan Z, Xue X, et al. High expression of galectin-1 in pancreatic stellate cells plays a role in the development and maintenance of an immunosuppressive microenvironment in pancreatic cancer. Int J Cancer. 2011 Epub ahead of print. 10.1002/ijc.26290

112. Soldati R, Berger E, Zenclussen AC, et al. Neuroblastoma triggers an immunoevasive program involving galectin-1-dependent modulation of $\mathrm{T}$ cell and dendritic cell compartments. Int $\mathrm{J}$ Cancer. 2011 Epub ahead of print. 10.1002/ijc.26498

113. Dardalhon V, Anderson AC, Karman J, et al. Tim-3/galectin-9 pathway: regulation of Th1 immunity through promotion of CD11b+Ly-6G+ myeloid cells. J Immunol. 2010; 185:13831392. [PubMed: 20574007]

114. Demotte N, Wieërs G, Van Der Smissen P, et al. A galectin-3 ligand corrects the impaired function of human CD4 and CD8 tumor-infiltrating lymphocytes and favors tumor rejection in mice. Cancer Res. 2010; 70:7476-748. [PubMed: 20719885]

115. Tsuboi S, Sutoh M, Hatakeyama S, et al. A novel strategy for evasion of NK cell immunity by tumours expressing core2 $O$-glycans. EMBO J. 2011; 30:3173-3185. [PubMed: 21712812]

116. Nicoll G, Avril T, Lock K, et al. Ganglioside GD3 expression on target cells can modulate NK cell cytotoxicity via siglec-7-dependent and -independent mechanisms. Eur J Immunol. 2003; 33:1642-1648. [PubMed: 12778482]

117. Ohta M, Ishida A, Toda M, et al. Immunomodulation of monocyte-derived dendritic cells through ligation of tumor-produced mucins to Siglec-9. Biochem Biophys Res Commun. 2010; 402:663669. [PubMed: 20971061] 


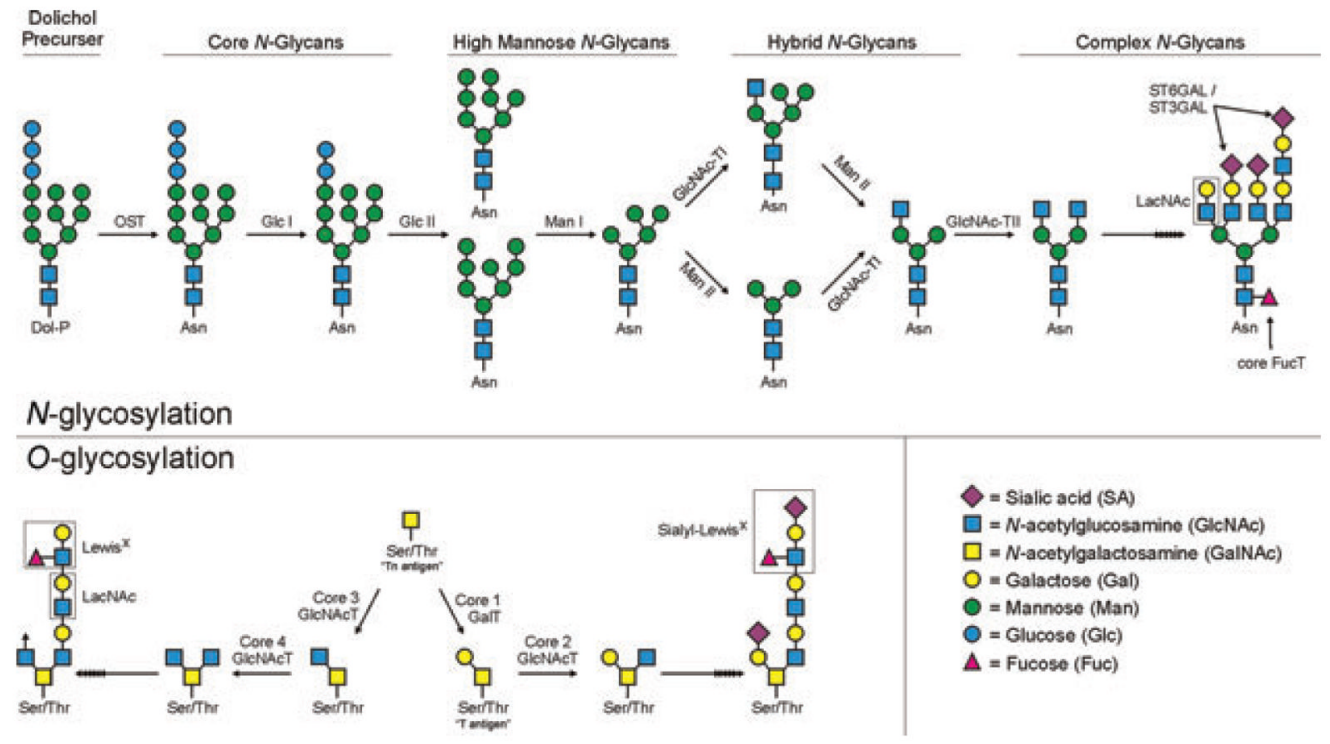

Figure 1.

Schematic of the N- and O-linked glycosylation pathway in mammals. (Top) The asparagine (N)-linked pathway begins in the endoplasmic reticulum (ER), where OST

(oligosaccharyltransferase) moves the core $N$-glycan from the dolichol precursor to an asparagine residue with the $\mathrm{N}-\mathrm{X}-\mathrm{S} / \mathrm{T}$ consensus sequence. This structure is trimmed by glucosidases (Glc I and Glc II) within the ER, which assist in the folding quality control system mediated by the calnexin/calreticulin pathway. Once released from this quality control, the nascent glycoprotein traffics to the Golgi apparatus where further trimming occurs initially, which is then followed by the creation of significant diversity through addition of other saccharides by a variety of transferases (" $\mathrm{T}$ " in the abbreviations) in a nontemplate-driven process. Another key addition are 2,3-linked and 2,6-linked terminal sialic acids, which are critical for a number of biological functions. Finally, the LacNAc disaccharide unit ( $N$-acetyllactosamine) is a key recognition site for a number of glycanbinding molecules, including some of the galectin family. (Bottom) The serine/threonine (O)-linked glycosylation pathway is distinct from the N-linked pathway in a number of ways. The nature of the linkage and the enzymes involved are separate, and the resulting structures are quite divergent, although some similarities exist, such as the presence of the LacNAc unit. The O-linked glycans are broken down into core subgroups and carry names like "Tn antigen" and "Sialyl-Lewis" $\mathrm{x}$ " that are common in the literature. These have been labeled for reference. 


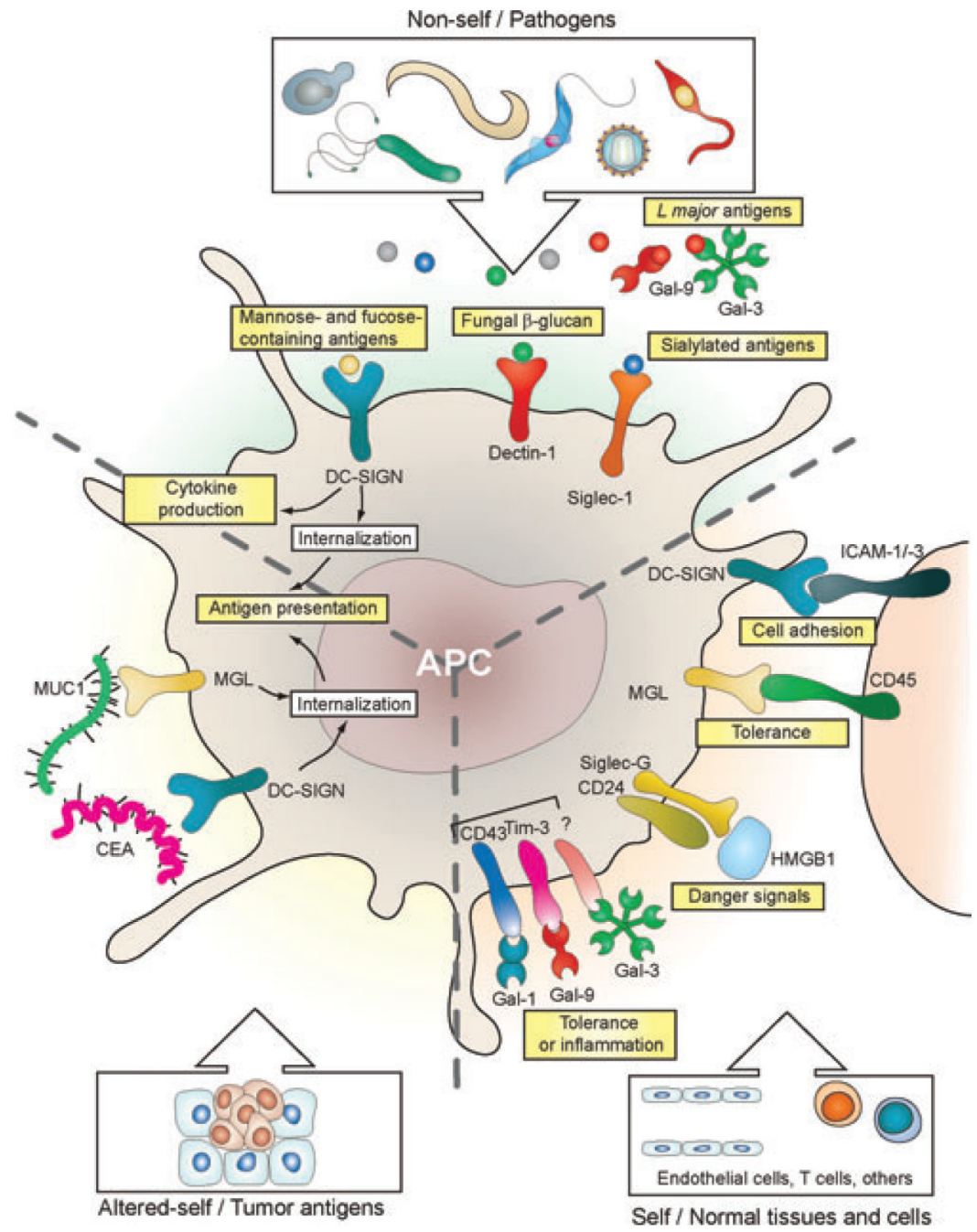

Figure 2.

Lectin-glycan interactions in innate immunity: Discrimination of non-self, altered-self, and self by antigen-presenting cells (APCs). GBPs (e.g., DC-SIGN, Dectin-1, siglec-1, galectin-3 (Gal-3), galectin-9 (Gal-9)) can function as pattern recognition receptors (PRR) through the recognition of non-self glycans exposed on different pathogens, including viruses, bacteria, yeasts, and parasites. In particular those CLRs with glycan specificity for Lewis and mannose glycans (such as DC-SIGN) have been shown to bind a multitude of pathogens such as HIV-1 and other viruses, bacteria such as Mycobacterium tuberculosis and Helicobacer pylori, helminths such as Schistosoma mansoni, and yeasts such as Candida albicans. On the other hand, Gal-3 and Gal-9 play key roles as soluble PPRs by discriminating Leishmania species. Also, CLRs (e.g., MGL, DC-SIGN) can detect changes in glycosylation of certain tumor-associated antigens, such as the carcinoma embryonic antigen (CEA) and $\mathrm{MUC1}$ occurring during onco-transformation and tumor progression. These changes include increased expression of the Lewis blood group family of antigens, particularly $\mathrm{Le}^{\mathrm{x}}$, and $\mathrm{Le}^{\mathrm{y}}$, that are often associated with poor prognosis of the tumor. This recognition allows antigen internalization, presentation to $\mathrm{CD} 4^{+} \mathrm{T}$ cells, cross-presentation to $\mathrm{CD} 8^{+} \mathrm{T}$ cells, and potentiation of antitumor immunity, although in some cases these interactions can also lead to inhibition of $\mathrm{T}$ cell responses. In addition, GBPs may play important roles in self-recognition in a variety of cellular processes, including (among 
others) cell adhesion (DC-SIGN-ICAM1/3 interactions), T cell signaling (MGL interactions with GalNAc-expressing CD45 glycoforms), discrimination of danger signals (interactions among siglec-G, CD24, and the HMGB1 alarmin), and modulation of immunogenic or tolerogenic APC programs (e.g., interactions between galectins and APC glycoproteins, such as Tim-3 and CD43). 